\title{
Governance and Capacity Building in German and Austrian Public Health Since the 1950s
}

\author{
Horst Noack Dr.med., $\mathrm{PhD}^{1}$
}

\begin{abstract}
The German speaking countries (Germany and Austria) have a strong tradition of universal health insurance since the late 19th century. Germany was one of the leading countries in "social hygiene as health science", an interdisciplinary field of academic work, health policy and practice, providing a comprehensive scientific basis both for professional education and training in the new academies for social hygiene, the schools of public health in the 1920s, and also for a rapidly growing network of municipal public health services. Public health in Austria at that time was less advanced. There was a rupture in the field of public health in these countries as the Nazi regime and World War II destroyed almost all of the human resources, the scientific basis and the institutional infrastructure required for advancement.

In the postwar period Germany was divided with separate social and health systems in East and West Germany until reunification in 1990. Meanwhile, Austria became a democratic federal republic developing a social welfare policy on the basis of a successful economy. Whereas Germany set up national programmes to support the development of a new public health, Austria established a health promotion fund. As a result, there has been more growth in the public health community in Germany than in Austria. However, in both countries strong efforts to strengthen the educational base will be needed to address the complex issues facing public health in the 21st century. For example, health expenditures in Germany and Austria are among the highest in the European Union, but health systems indicators such as healthy life years show values below the European average. The challenge to renew the highly fragmented systems of health/disease care and improve the social determinants of population health underline the need for strengthening public health structures and national policy in the two German speaking countries. Development of the scientific community is underway but has not yet reached the levels of the outstanding achievements of the late 19th and early 20th centuries.
\end{abstract}

Key Words: Social hygiene, health sciences, public health functions, public health medicine, governance, capacity building

\footnotetext{
${ }^{1}$ Medical University, Graz, Austria.
}

Correspondending Author Contact Information: Dr. Horst Noack at horst.noack@ medunigraz. at; Medical University Graz, ULG Public Health, Universitätsplatz 4/3, 8010 Graz, Austria. 
Recommended Citation: Noack H. Governance and Capacity Building in German and Austrian Public Health Since the 1950s. Public Health Reviews. 2011;33:26476.

\section{INTRODUCTION}

At the end of the 19th and in the early 20th century, Germany was seen as one of the leading countries in the development of social hygiene, as well as of Bismarckian social health insurance. During this time period, public health led to many scientific breakthroughs such as those of microbiologist Robert Koch, and the epidemiologist and highly influential civil servant Adolf Gottstein, making public health a cross-sectoral field. ${ }^{1}$ Austrian public health followed a similar course, but was less advanced. These "golden years" of public health in Germany came to a sudden end in 1933 when the Nazi Party seized power. With the forcible incorporation of Austrofascism into the First Austrian Republic in 1934 the conditions for ongoing development of the field deteriorated rapidly in this country as well.

During the Nazi period of 1933 to 1945 , the Hitler regime preached many aspects of "public hygiene", but in reality the science base in the biological fields was stricken by the elimination of Jewish contributors through expulsion and murder. Simultaneously, public health was complicit in the corruption of eugenics leading to the mass murder of "inferiors". In response to these atrocities, the Nuremberg Doctors Trials of 1946 helped to set new ethical standards for research behaviour protecting participant's rights.

Since the establishment of federal democratic states in 1949 and 1950 both countries have achieved high levels of economic growth, social security and standards of living. They have established extensive and highly differentiated systems of health/disease care and health expenditures have risen to more than ten percent of Gross Domestic Product (GDP). ${ }^{2}$ However, both countries lag behind in the development of public health governance as that in comparable European countries, Austria to an even greater extent than Germany. Public health governance has been largely concerned with governance of medical and nursing care while the academic field of capacity building, research, education and training in new public health has existed in Germany only since the late 1980s, and in Austria, to a lesser extent, since 2002.

This review aims to explore the governance structures and activities in both countries. It describes, contrasts and discusses capacity building efforts for a new public health in Germany and Austria, with recommendations to strengthen the public health infrastructure, including education of the public health workforce to meet the challenges of the $21^{\text {st }}$ century. 


\section{A THEORETICAL FRAMEWORK}

Public Health has been defined as "collective action for sustained population-wide health improvement" 3 offering a new vision both of individual and collective health. ${ }^{4}$ As with other fields, it has entered into an era of rapid global changes that may have an impact on the economic, social and environmental determinants of population-wide health development.

Public health theory as developed by international and national organisations includes three broad conceptual frameworks: Governance of Health and Health Systems, the Public Health Action Cycle, and Capacity Building Activities to implement public health efforts into societal and organisational practice.

Governance of Health and Health Systems is more than just management and constitutes leadership through direction and support of organisational change. Health systems governance refers to activities explicitly organised by society such as the Public Health Action Cycle. The distinction can be a subtle one as the debate on the contribution of medical care to the rise of life expectancy has shown.

The Public Health Action Cycle as defined by the Institute of Medicine of the United States National Academies of Sciences comprises three Core Functions of public health: Assessment, Policy Development, and Assurance. Each core function encompasses more specific public health activities defined as Essential Public Health Services to fulfil the core functions of public health (Table 1). ${ }^{5}$

Table 1

Public health core functions and essential public health services

\begin{tabular}{c|l}
\hline Core Functions & \multicolumn{1}{c}{ Essential Public Health Services } \\
\hline \multirow{2}{*}{ Assessment } & $\begin{array}{l}\text { Monitor health status } \\
\text { Diagnose and investigate health problems }\end{array}$ \\
\hline \multirow{3}{*}{$\begin{array}{c}\text { Policy } \\
\text { Development }\end{array}$} & $\begin{array}{l}\text { Inform, educate, and empower people } \\
\text { Mobilise community partnerships } \\
\text { Develop policies and plans } \\
\text { Enforce laws and regulations }\end{array}$ \\
\hline \multirow{3}{*}{ Assurance } & $\begin{array}{l}\text { Link people to needed personal health services } \\
\text { Assure a competent workforce }\end{array}$ \\
& Evaluate effectiveness, accessibility and quality health services \\
& Research for new insights and innovative solutions to health problems. \\
\hline
\end{tabular}


Capacity Building Activities. Governments or organisations planning a new public health policy may not be ready to implement innovation and change. Capacity building in public health aims to enhance the abilities of providers of health care or health promotion programmes to achieve measurable and sustainable results and to make them aware of the potential obstacles involved. ${ }^{6}$ Capacity building in public health frequently involves national, state and often international level organizations to support research, education and training programmes, while organisational or community level small groups and individuals are necessary to plan, develop and conduct such programmes and to participate in them.

\section{PUBLIC HEALTH GOVERNANCE IN GERMANY AND AUSTRIA}

The German and Austrian health care systems have maintained a high degree of continuity since the reforms in the 1880s when the Bismarck model of Social Health Insurance (SHI) was established in both countries to provide universal health care, financed and largely governed by statutory sickness funds. Many other countries also later adopted this type of health care governance. In this model, social health care organisations are associations of statutory sickness funds, hospitals, physicians, nursing homes and suppliers providing universal health care and acting both as payers and purchasers. Basic principles of the system are solidarity in population-wide coverage of health care, pluralism in actors, organisational structure, a corporatist model of negotiations, and participation in shared governance arrangements, ${ }^{7}$ but not explicitly the core functions of public health.

After World War II, both Germany and Austria built extensive and differentiated systems of medical care. As in all European countries health expenditure as a share of GDP has risen. Both in Germany and Austria up to 10.5 percent of GDP (EU $8.3 \%$ ) was spent on health care in $2008^{2}$ (Figure 1) and this grew further to 11.5 percent and 11.0 percent respectively in 2009. ${ }^{8}$ Meanwhile, expenditure on organised public health and prevention programmes in 2008 represented only 3.7 percent of total expenditure on health in Germany and 1.8 percent in Austria (EU $2.9 \%$ ). ${ }^{2}$

Governance of the health system is shared amongst the federal government, the regional state (Länder) governments (16 in Germany with 81.80 million people, 9 in Austria with 8.38 million people), corporatist organisations of sickness funds, the Chambers of Physicians, Dentists and Pharmacists, and other legitimised civil service organisations. Governance structures in public health in the two countries are highly complex and 


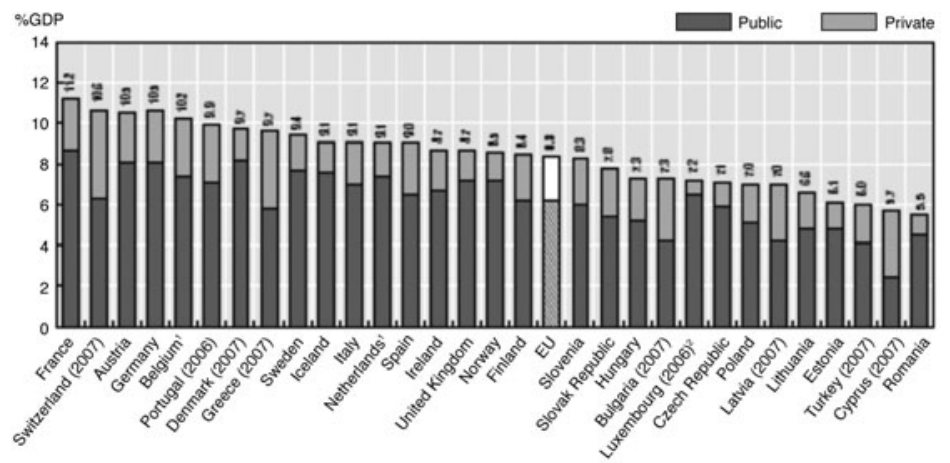

Fig. 1. Total health expenditure as a share of GDP, 2008.

${ }^{1}$ Public and private expenditures are current expenditures (excluding investments).

${ }^{2}$ Health expenditure is for the insured population rather than resident population.

Source: OECD Health Data 2010; Eurostat Statistics Database; WHO National Health Accounts. Available from URL: http://www.oecd-ilibrary.org/ (Accessed 19 September, 2011).

difficult to describe. Aside from ministries at federal and state levels, they include a large number of governmental, non-governmental and academic institutions and in principle all providers of health/disease and nursing care at the state level. ${ }^{9,10}$ Binding health and health care targets are not yet explicitly defined and quality standards differ. As a result, most organisations tend to act quite autonomously according to their own norms, rules and guiding principles. Since the 1990s, government and health insurance organisations in Germany and Austria have been increasingly concerned with health care financing and expenditure planning. Despite political will and several reforms, health expenditure has risen continuously, a trend observed in most OECD countries since the 1970s. ${ }^{11}$ Political will and reform measures are no substitute for effective political instruments.

\section{THE PUBLIC HEALTH ACTION CYCLE AND THE CORE FUNCTIONS OF PUBLIC HEALTH}

How well do the health care systems in Germany and Austria fulfil the core functions of public health? A quick assessment by the author, based on reported information and personal knowledge, of the essential public health services (Table 1) indicates:

- Assessment is not a common tool in health policy and planning: policy decisions are seldom based on diagnosed community health problems. 
- Policy development in public health does not seem to be an active field. School curricula rarely promote individual and social empowerment, or bottom-up community efforts to develop local health policies. Health promotion and disease prevention are rarely embedded in top-down regional health policies.

- Assurance of available and accessible health/disease care services seems adequate except for some parts of eastern Germany. However, Germany and Austria both have a serious shortage of qualified public health professionals and community nurses. In Germany health services research is growing; in Austria it is still in the planning stages.

Industrial modernisation of living conditions and social life over the last 100 years $^{12,13}$ has led to an unprecedented and accelerated increase in life expectancy. In both countries, it grows between two and three months per year. Out of the EU19 countries, Germany and Austria rank sixth and seventh in average life expectancy at birth, while ranking only $12^{\text {th }}$ or $13^{\text {th }}$ out of the EU15 in health expectancy. Elderly people in Germany and Austria tend to enjoy significantly fewer healthy life years as compared to the elderly in many other European countries. There is a moderate association between health spending per capita and healthy life years (Figure 2); however, the relatively low ranking in healthy life years seems unimpressive considering the high level of health expenditure in both countries.

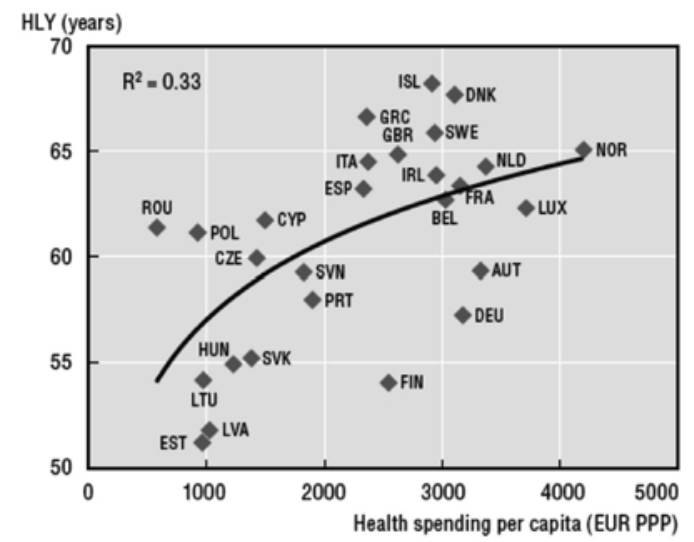

Fig. 2. Healthy life years (HLY) at birth, 2005-2007, and health spending per capita, 2007.

Source: European Health and Life Expectancy Information System (EHLEIS); OECD Health Data 2010; Eurostat Statistics Database; WHO. Available from URL: http://www.oecd-ilibrary.org/ (Accessed 19 September, 2011). 
In both countries environmental protection against old and new health hazards and sanitary supervision of health care settings and health-related public goods tends to be of minor concern, as long as no threat of a population-wide epidemic exists. The recent E. coli outbreak cqusing haemolytic uraemia revealed the need to strengthen public health structures.

Within the German and Austrian public health communities there seems to be consensus that the three core functions of public health, namely, Assessment, Policy Development, and Assurance, are only faintly implemented in the public health systems of the two countries. Public health is almost synonymous with public health medicine, including medical and hospital care. The two health care systems still consist of two quite independent subsystems:

1. A public hospital sector governed by the States and private nonprofit providers such as church organisations and in Germany by a growing for-profit hospital sector.

2. An ambulatory sector governed by mostly single-handed private general practitioners and medical specialists as well as out-patient hospital departments and in Austria, ambulances governed by the sickness funds.

About three quarters of health care expenses, both for the public hospital sector and the ambulatory care sector are financed by public funds and one quarter by private funds. Approximately 50 percent (Austria) and about 60 percent (Germany) of health care expenses are supplied by sickness funds with the remaining part of public expenses supplied by governments. Hospitals are paid according to diagnosis-related group (DRG)-systems rules. Ambulatory care providers are paid mainly on the basis of fee-forservice arrangements, which are regularly negotiated with the sickness funds. The governance structures of the German and Austrian health care systems are highly differentiated, fragmented and extremely complex and hence not very transparent. ${ }^{9,10}$

The weak core functions imply weak governance, with resulting moderate or low systems performance and unsatisfactory outcomes. Studies in the field of health systems research have identified a number of weaknesses of the German and more recently also of the Austrian health systems. ${ }^{14,15}$ They may be summarised by the following statements:

- Low level of awareness of the health needs of sizable population groups;

- Lack of recognition of the challenge to reduce social inequalities;

- Failure to run a highly expensive system on the basis of insufficient knowledge and evidence;

- Failure to build a monitoring systems to observe and discuss changes in key indicators; 
- Failure to evaluate the quality and outcomes of the health care and health promotion programmes and to learn from the results;

- Challenges to reach broad consensus on the overall perspective, the general goals and the specific targets of the health system;

- Challenges to renew and strengthen the legal basis of health care and social health policies;

- Challenges to reduce high levels of concomitant oversupply, undersupply and potentially unsafe supply of health care services;

- Challenges to reach a better balance between disease prevention and health promotion and curative care;

- Challenges to build sufficient public health capacities by scientific health research and public health education and training;

- Challenges to strengthen organisation development and sustainability.

These weaknesses are by no means unique to the German and Austrian health systems. In fact many of them appear to be part and parcel of most modern health systems and they do not necessarily imply that the two systems are devoid of any particular strengths. For example, in a European survey 92 percent of the Austrian sample and 65 percent of the German sample were "very satisfied" or "fairly satisfied" with their national health care systems. ${ }^{16}$

\section{CAPACITY BUILDING FOR PUBLIC HEALTH}

Between 1985 and 2002 the German federal government commissioned two national programmes to support the development of public health. The first was a scholarship programme providing over 200 graduates in Medicine, Social Science, Biology or other fields with the opportunity to study public health and earn a Master of Public Health (MPH) or PhD degree from universities in the US, the United Kingdom and other countries. This initiative was followed by a ten-year research programme to establish five regional Public Health Research Networks (Forschungsverbünde) involving 16 universities as active partners and over 200 research projects in many fields of public health. Some of these networks have been able to continue research programmes though at a less ambitious level. Despite this considerable investment in the development of public health research, Germany still ranks low in the European Region. ${ }^{17}$

Tying in with the tradition of social hygiene as a health science which was already a relatively well developed academic field of research and teaching in the 1920s, the new cross-disciplinary field was designated 
"health sciences / public health". In the German-speaking countries both terms tend to be used synonymously today. In the late 1980s eight German universities started master's programmes in Health Sciences (Gesundheitswissenschaften). In 1991/1992 the University of Bielefeld established the first German Faculty of Health Sciences (School of Public Health). ${ }^{18}$ Today, German universities offer 15 accredited master's programmes in Public Health. Curricula cover a wide spectrum of public health content ranging from public health medicine to comprehensive programmes in a New Public Health. Universities of Applied Sciences offer over 100 programmes in Social Medicine and New Public Health to educate and train public health workers, health care managers, academic nurse practitioners and other professional groups. ${ }^{19}$

The legal and political conditions for building a New Public Health in Austria have been less favourable than in Germany. There has never been a national funding policy for public health, and the law requires universities to finance postgraduate education and training solely from students' fees. The first postgraduate master's programme with a curriculum designed to meet the European standards started in 2002 at the Medical University of Graz. It was made possible through grants and scholarships from the State of Styria (Steiermark), the Fund for a Healthy Austria (Fonds Gesundes Österreich (FGÖ) and the Federation of Austrian Social Insurance Institutions (Hauptverband der österreichischen Sozialversichungsträger (HSVT). A second course programme was started in 2007 at Schloss Hofen Centre for Continuing Education in the State of Vorarlberg. Despite limited scientific resources, it was possible to educate and train over $150 \mathrm{MPH}$ students on the basis of contracts with many academic teachers from other Austrian and European universities.

In subsequent years the University of Vienna together with the Medical University of Vienna and the University of Linz established more specific training programmes in public health. None of these programmes has been accredited so far and because of a lack of substantial investment into basic infrastructure, accreditation cannot be expected soon

Aside from these public efforts the Private University for Health Sciences and Heath Technology Assessment in Hall/Tyrol offers an education and training programme, in principle, at all three academic levels. In addition, five Universities for Applied Sciences have developed bachelor and master's level education and training programmes to qualify practitioners for health promotion, disease prevention and health care management. 
A long-standing weakness of the public health sector in Austria is its lack of an adequate scientific knowledge base. In 2002 and 2007, the Ludwig Boltzmann Society, the leading national funding organisation for applied research, established institutes for Health Technology Assessment and Health Promotion Research in collaboration with federal and regional ministries, FGÖ and social insurance organisations. The Austrian Public Health Association (ÖGPH) was founded in 1995 as a multidisciplinary forum to support the development of research, education and training and practice in the field. ${ }^{20}$

It is important to acknowledge the international involvement in the establishment of both the German and the Austrian education and training programmes in public health. Many of these programs were stimulated by the European Office of WHO and particularly by the First International Conferences on Health Promotion in November 1986 in Ottawa, Canada where a new perspective for public health in the $21^{\text {st }}$ century was discussed. Conference participants initiated activities leading to the establishment of the Faculty of Health Sciences at the University of Bielefeld and of the MPH programmes in the two countries.

Education and training programmes in public health in Germany and Austria are at different stages of development. It is known that they cover health care and health promotion in different ways and to varying degrees of detail. Their contribution to capacity building for the new public health is, of course, difficult to judge.

\section{CONCLUSIONS}

Health systems governance has developed in a pragmatic way in both Germany and Austria. However, a new public debate has begun on the question of how much and what kind of governance is needed. Stakeholders and users of the health system tend to hold a wide range of opinions ranging from no governance at all to elaborate regulation of the system. The best and perhaps only strategy to find an acceptable answer is a 'reality test' implemented through a well-founded strategy with an evaluation of its outcomes. Issues that require legislation and regulation such as smoking reduction, heavy alcohol consumption, and food safety have been a challenge. The 2011 outbreak of E. Coli in northern Germany has called into question the adequacy of governing and regulatory structures in basic public health services. 
- There is ample evidence showing that health care should no longer be the sole public health strategy in Germany and Austria. Major and sustained efforts are needed to build an effective governance structure for population-wide health promotion and primary prevention based on the assessment of health need.

- The German and Austrian health systems are by no means ready to start developing governance structures to oversee public health governance, which requires a long-term strategy of structural and workforce capacity building. This should include public health and basic science research, workforce development and organisational development.

- Germany and to some degree Austria once led in public health development but were severely crippled by the terrible events of the two world wars of the $20^{\text {th }}$ century and the atrocities of the Nazi regime. Research and public health relied on universal medical care insurance for ambulatory and hospital services, while the health regulatory and health promotion functions lagged behind other countries in Europe.

- The German and Austrian health systems are expensive in that the percentage of GDP going to health is among the highest in Europe, while the life expectancy and other outcome indicators are not so highly placed.

- Neither the German and the Austrian Constitutions nor the health laws of the two countries provide a sufficient legal basis for a public health strategy serving the human asset, a sector of society in which the two countries already invest over ten percent of their national income.

- As seen in some of the Scandinavian countries, developing the future health system deserves a long-term political effort to agree on a vision and a binding long-term strategy involving the Federal and State Parliaments and Governments, the health and health care sciences, the health and education profession and most important of all the public. The outcome of this process should be to develop a future-oriented legal basis for a New Public Health. ${ }^{21}$

Conflicts of Interest: None declared.

\section{REFERENCES}

1. Heinzelmann W. Sozialhygiene als Gesundheitswissenschaft. Die deutsch/ jüdische Avantgarde 1897-1933. Eine Geschichte in sieben Profilen. Bielefeld: transcript Verlag; 1990.

2. OECD. Health at a glance: Europe 2010. Available from URL: http://www.oecdilibrary.org/social-issues-migration-health/health-at-a-glance-europe-2010_ health_glance-2010-en (Accessed 3 July, 2011). 
3. Beaglehole R, Bonita R, Horton, Adams O, McKee M. Public health in the new era: improving health through collective action. Lancet 2004; 363: 2084-86 (Accessed 24 June, 2011).

4. Antonovsky A. Unraveling the mystery of health - how people manage stress and stay well. San Francisco: Jossey-Bass Publishers; 1987.

5. American Public Health Association (APHA). Essential Public Health Services. Available from URL: http://www.apha.org/programs/standards/ performancestandardsprogram/resexxentialservices.html (Accessed 25 June, 2011).

6. Hawe P, Noort M, King L, Jordens C. Multiplying health gains: the critical role of capacity-building within health promotion programs. Health Policy 1997; 39: $29-42$.

7. Saltman RB. Social health insurance in perspective: the challenge of sustaining stability. In: Saltmann RB, Busse R, Figueras J (eds.). Social health insurance systems in western Europe. New York: Open University Press, McGraw-Hill; 2004: 3-20. Available from URL: http://www.euro.who.int/_data/assets/ pdf_file/0010/98443/E84968.pdf (Accessed 14 September, 2011).

8. OECD Health Data 2011. Health expenditure and financing 2010. Available from URL: http://stats.oecd.org/index.aspx?DataSetCode=HEALTH_STAT (Accessed 14 September, 2011).

9. Busse R, Riesberg A. Health care systems in transition: Germany. WHO Regional Office for Europe on behalf of the European Observatory on Health Systems and Policies. Copenhagen; 2004 (Accessed 27 June, 2011).

10. Hofmarcher MM, Rack H-M. Austria: health system review. Health systems in transition. 2006; 8(3):1-247. Available from URL: http://www.euro.who. int/_data/assets/pdf_file/0009/96435/E89021.pdf (Accessed 27 June, 2011).

11. Organisation for Economic Co-operation and Development (OECD). Change of health expenditures in OECD countries. Available from URL: http://www.oecd. org/document/38/0,3746,en_21571361_44315115_48289894_1_1_1_1,00. html (Accessed 14 September, 2011).

12. Beck U. Weltrisikogesellschaft. Frankfurt am Main: Suhrkamp; 2007.

13. Beck U, Giddens A, Lash S. Reflexive modernisation: politics, traditions and aesthetics in the modern social order. Cambridge: Polity Press; 1994.

14. Rosenbrock R, Gerlinger T. Gesundheitspolitik. Eine systematische Einführung, 2. Auflage. Bern: Huber; 2006.

15. Hauptverband der österreichischen Sozialversicherungsträger, The London School of Economics and Political Science, April 2010. Available from URL: http://www.hauptverband.at/mediaDB/683474_01_LSE_Public\%20 Health\%20Overview\%20report (Accessed 3 July, 2011).

16. Bleich SN, Özaltin E, Murray CJL: How does satisfaction with the health-care system relate to patient experience? Bulletin of the World Health Organization 2009;87:271-278. Available from URL: http://www.who.int/bulletin/ volumes/87/4/07-050401-table-T1.html (Accessed 9 April, 2011). 
17. McCarthy, Clark A (Guest eds). Public health research literatures in Europe. European Journal of Public Health. 2007;17(Suppl 1): 1-49.

18. Dierks M-L. Postgraduierte Public-Health-Ausbildung und Berufsfelder im Bereich von Public Health. In: Schwartz FW, Badura B, Leidl R, Raspe H, Siegrist J, Walter U (Eds.). Public Health. Gesundheit und Gesundheitswesen. München Jena: Urban \& Fischer: 772-779.

19. Kälble K. Gesundheitsberufe unter Modernisierungsdruck. In: Pundt J (Ed.). Professionalisierung im Gesundheitswesen. Positionen - Potenziale Persepektiven. Bern: Verlag Hans Huber; 2006. Pp. 213-233.

20. Austrian Public Health Association. Österreichische Gesellschaft für Public Health (ÖGPH). Available from URL: http://www.oeph.at/public-health-inoesterreich/public-health-faq (Accessed 5 July, 2011).

21. Tulchinsky TH, Varavikova EA. The New Public Health. Public Health Reviews. 2010; 32: 25-53. 